\title{
Targeting sedentary behaviour for behavioural change: Opportunities for new strategies
}

\author{
P J-L Gradidge, MSc, PhD \\ Centre for Exercise Science and Sports Medicine (CESSM), Faculty of Health Sciences, University of the Witwatersrand, Johannesburg, South Africa
}

Corresponding author: P J-L Gradidge (philippe.gradidge@wits.ac.za)

Background: The South African online population is rapidly transforming into one which is always reachable. The economic benefits of this transition are vast; however, the impact on obesity and related diseases is potentially devastating

Discussion: In this commentary it is proposed that public health strategies be revisited to align with the contemporary digital evolution, particularly as increased web-based applications suggest higher amounts of sitting times.

Conclusion: It is necessary to gain a better understanding of the different domains of sedentary behaviour, and the manner in which they interact, to begin to develop strategies to reduce sitting time, and thereby reduce cardiovascular disease risk.

Keywords: internet; health; obesity; South Africa; intervention

S Afr I Sports Med 2017; 29:1-2.DOI: 10.17159/2078-516X/2017/v29i0a1632

Sedentary behaviour is defined as time spent sitting during waking hours, particularly a metabolic equivalent (MET) level of "energy expenditure $\leq 1.5$ times the metabolic rate while in the sitting or reclining position".[1] Most of this sedentary behaviour occurs within the context of activities of daily living. Instruments used to measure sedentary behaviour can vary in different regions, such as the Sedentary Behaviour Questionnaire which captures time spent in various types of sedentary activities. However, in the South African context researchers may need to adapt items for the appropriate culture or language. This suggests that there is need for standardised sedentary behaviour instruments and nomenclature that address the paradox of sitting time in South Africa.

Recently, sitting time has been shown to be strongly and independently associated with all-cause mortality in persons, even after adjusting for physical activity time. ${ }^{[2]}$ Only the most physically active persons were "protected" from the increased risk associated with sedentary behaviour. On average, South Africans have a high level of sedentary time, ${ }^{[3]}$ and the economic growth of the country has made the purchasing of sedentarypromoting assets more affordable for the large majority, including internet accessible devices. There is little understanding of how this transition influences health outcomes for this country.

With the global shift of people into various centres of activity, and the continual development of web-based applications, the majority of global populations is now characterised by increased sitting times. Urbanised populations are often nudged into sedentary thinking patterns by well-planned marketing strategies in the form of audiovisual stimuli to influence this behaviour. ${ }^{[4]}$ The working environment is not dissimilar, and sitting for extended periods can be viewed as fundamental to worker productivity by line managers. ${ }^{[5]}$ In South Africa, the proportion of internet users actively engaged in accessing the internet is increasing at a rapid rate. Recent data show that the proportion of internet users in the country has increased from $8 \%$ of the total population in 2006 to $52 \%$ in 2016. ${ }^{[6]}$ The social media platform has also grown substantially, so that the majority of people connected to the internet do so via mobile devices. ${ }^{[7]}$

The National Development Plan 2030, adopted by the South African Government, includes information, technologies and communication (ICT) as part of its priorities. ${ }^{[8]}$ The vision for the ICT sector of the country is to enhance the current infrastructure and reduce the "digital divide". Government has pledged to provide financial support for this initiative, and is in favour of lowering connectivity costs and improving ICT standards. Although policies to improve technological infrastructure may lead to a united country, these could have unintended health consequences, such as increasing the sitting time while connected to the internet.

\section{Supportive mechanisms for behaviour change}

The private healthcare sector of South Africa demonstrates that incentivised programmes can assist with obesity reduction in the country by rewarding healthy behaviours. ${ }^{[9]}$ For those in the higher income categories, this may be in the form of digital healthcare and wearable devices which have provided the healthcare industry with evidence of adherence to such programmes. However, these data are usually delivered through internet-based applications which may result in increased sedentary time whilst connected to the internet. Another dilemma is that most South Africans still do not have adequate access to healthcare which can sometimes result in unintended consequences. For example, in 2009 one of the largest private healthcare providers in South Africa launched an incentivised programme to encourage purchases of healthier food products with the intention of lowering BMI; however, this programme was shown to be regressive because the target population already has access to private healthcare while the public health care sector has no comparable programmes. ${ }^{[10]}$ Similarly, access to fitness facilities does not necessarily have an inverse linear relationship with obesity, and neither can dietary recommendations guarantee positive outcomes for disease reduction. The fact that the obesity epidemic in South Africa continues to worsen suggests that incentive-based programmes alone may not be the best answer for the reversal of this epidemic. In a country undergoing a rapid internet-based transition, it is even more important to explore plausible solutions for sustainable behaviour change.

\section{Contextualised solutions}

The recent evidence from the series in The Lancet on physical activity confirms that sitting time is associated with obesity and related cardiovascular disease risk, but this relationship can be weakened with physical activity. ${ }^{[2]}$ Sedentary behaviour is composed of various interconnected constructs, and the understanding of how these components interact with each other is limited. It is also important to identity the effects of these respective indicators on cardiovascular disease. 
The following recommendations can assist with managing the problem of continuous screen time during waking hours:

- The current public health solutions aimed at addressing obesity are prescriptive and not well-maintained. It is therefore recommended that interrupted screen time with less sitting be encouraged in workplaces, particularly in those industries that necessitate adherence to web-based services. In the home, an attitude towards lowering sedentary time could be shaped with supplemented physical activities within the family.

- The next recommendation is more complex as it requires a complete paradigm shift towards active commuting. Some South African cities have already started to alter the road infrastructure to encourage travel-related physical activity; however, these routes have not been maintained and, in some instances, dedicated cycle lanes are used for normal road traffic. The concept of active commuting can also be influenced by urban planners to reduce vehicular congestion in the major cities. Since many people in South Africa currently use public transport, ${ }^{[11]}$ walking to a destination might be the healthy alternative, provided that it can be done in safety.

- The internet has evolved rapidly over time and the emergence of web-based applications has narrowed the rift of societal diversity in South Africa. The solutions for addressing sitting time within this construct needs to encompass all spheres of society, age and socioeconomic strata. For example, the higher socioeconomic stratum already engages in exercise programmes using tracking applications that provide virtual rewards for achieving monthly training objectives. Developers of such applications and public health experts can follow this example by proposing similar rewards-based programmes to all population groups.

- Finally, behavioural economists use game theory to test real world social situations to assist with convergence towards certain behaviours such as purchasing preferences with regard to online shopping. Policymakers can use these and other comparable evidence-based strategies to influence positive behavioural change in internet users. These strategies must be closely monitored to ensure sustainability and success. In the South African context, this is particularly important given the growing demand for web-based services and the recent focus on the rise of cardiovascular disease risk factors.

\section{Conclusion}

Further investigation of the various domains of sedentary behaviour is recommended to fully understand the impact of internet based screen time on cardiovascular disease in the context of an expanding base of internet connected people.

\section{References}

1. Sedentary Behaviour Research Network. Letter to the Editor: Standardized use of the terms "sedentary" and "sedentary behaviours". Appl Physiol Nutr Metab 2012;37(3):540-542. [http://dx.doi/10.1139/h2012-024]

2. Ekelund U, Steene-Johannessen J, Brown WJ, et al. Does physical activity attenuate, or even eliminate, the detrimental association of sitting time with mortality? A harmonised meta-analysis of data from more than 1 million men and women. Lancet 2016;388(10051):1302-1310. [http://dx.doi/10.1016/S01406736 (16)30370-1]

3. Shisana O, Labadarios D, Rehle T, et al. The South African National Health and Nutrition Examination Survey, 2012: (SANHANES-1): the health and nutritional status of the nation.Pretoria: HSRC Press, 2014 http://www.hsrcpress.ac.za/product.php?productid=2314\&cat $=0 \&$ page $=1 \&$ fea tured\&freedownload $=1$

4. Basch $\mathrm{CH}, \mathrm{Kecojevic} \mathrm{A,} \mathrm{Cadorett} \mathrm{V,} \mathrm{et} \mathrm{al.} \mathrm{Sedentary} \mathrm{images} \mathrm{in} \mathrm{a} \mathrm{popular} \mathrm{US}$ based parenting magazine: 2010-2015. Health Promot Perspect 2016;6(2):55-57. [http://doi.org/10.15171/hpp.2016.10]

5. Gardner B, Smith L, Mansfield L. How did the public respond to the 2015 expert consensus public health guidance statement on workplace sedentary behaviour? A qualitative analysis. BMC Public Health 2017;17(1): 47 [http://10.1186/s12889-016-3974-0]

6. The World Bank Group. Internet users (per 100 people). Washington, DC: The World Bank Group, 2016 http://data.worldbank.org/indicator/IT.NET.USER.P2 (accessed 13 February 2017)

7. World Wide Worx, Ornico. SA Social Media Landscape 2017 http://www.worldwideworx.com/wp-content/uploads/2016/09/Social-Media2017-Executive-Summary.pdf (accessed 13 February 2017)

8. South African Government. Executive Summary. National Development Plan 2030: Our Future - make it work. Pretoria: National Planning Commission 2012. http://www.gov.za/issues/national-development-plan-2030

9. Lambert EV, Kolbe-Alexander TL. Innovative strategies targeting obesity and non-communicable diseases in South Africa: what can we learn from the private healthcare sector? Obes Rev 2013;14(Suppl 2):141-149. [http://dx.doi/10.1111/obr.12094]

10. Sturm R, An R, Segal D, et al. A cash-back rebate program for healthy food purchases in South Africa: results from scanner data. Am J Prev Med 2013;44(6):567-572. [http://10.1016/j.amepre.2013.02.011]

11. Lombard M, Cameron B, Mokonyama M, et al. Report on trends in passenger transport in South Africa. Midrand: Development Bank of South Africa, 2007. http://www.dbsa.org/EN/About-

Us/Publications/Documents/Report\%20on\%20Trends\%20in\%20Passenger\%20 Transport\%20in\%20South\%20Africa.pdf (accessed 17 March 2017) 